\title{
Dual-evaluation with formative peer-assessment by rubrics: A teaching experience in Business and Economics studies
}

\author{
Pilar Abad ${ }^{1}$, M-Dolores Robles ${ }^{2}$ \\ ${ }^{1}$ Universidad Rey Juan Carlos, Madrid, Spain. ${ }^{2}$ Economic Analysis, Universidad \\ Complutense de Madrid - ICAE, Madrid. Spain
}

\begin{abstract}
This paper shows the implementation of a learning experience based on formative peer feedback. The experience consists in the grading of an individual assignment using a dual-evaluation with peer's assessments method using rubrics. We develop this experience in a variety of subjects corresponding to three different Bachelor's degrees related to Business and Economics and gather the student's reflections about how this learning experience has influenced the acquisition and development of a set of generic competencies. Overall, students value positively the experience. In general, they consider that the ability to evaluate and maintain the quality of work produced and the determination and perseverance in the tasks given and responsibilities taken are the competencies most developed with this learning experience. This opinion is pervasive across the different characteristics of the students. Considering the kind of task, the ability to identify, pose and resolve problems is the competency most developed for the students that solve a practical exercise.
\end{abstract}

Keywords: Formative assessment; Peer feedback; Generic competencies; Dual assessment; Rubrics. 


\section{Introduction}

Learning methodologies must aim to develop student competencies at the same time knowledge is acquired. Martínez and Echevarría (2009) state that any kind of real convergence is not possible without major changes in pedagogical strategies. There is widespread acceptance that assessment needs to be changed to improve learning. The learning strategies must go hand in hand with an evolution in assessment systems. González and Wagenaar (2003) indicate that changes in teaching and learning approaches and objectives imply corresponding changes in assessment criteria and method. These modifications must not only take into consideration knowledge and content but abilities and generic competencies. The use of different evaluation parameters is, thus, widely recognized (De Miguel, 2009).

Implementation of on-going evaluation becomes a fundamental pillar in this process, in contrast to viewing assessment as the last part of the pedagogical process (Bloom et al., 1971). An ongoing learning approach highlights the role of formative evaluation which focuses on learning rather than marks/grades (Stiggins, 2002). Under this framework, lecturers must focus on facilitating formative evaluation and quality feedback to students, as opposed to becoming a mere knowledge transmission element. An effective and common way to articulate feedback on students work is the dual-evaluation method. This technique implies a double overview on students work before any mark is given. Several authors have confirmed the effectiveness of this type of feedback in experimental articles; among them are Covic and Jones (2008), Ellery (2008), Carless (2006), Gibbs and Simpson (2004) and Ashford-Rowe, Herrington and Brown (2014).

This article contributes to previous literature by developing a different design for experimental in-the-classroom assessment. The assessment material is based on practical tasks instead of lengthier assignments/essays. The students must work on their assignment on a given topic by putting together new concepts, analysis skills and drawing conclusions. When the first round of the task is completed, the student gets a mark as well as detailed feedback indicating mistakes/suggestions/comments on the work. They will also be given personalized orientation about how to improve their weak points. Dual-evaluation is then implemented by confronting students to the same task within a few days. Students dispose of a new opportunity to do the task but with more knowledge and skills to approach it.

Benefits associated to this double correction methodology in terms of learning can be offset by a main drawback: it increases dramatically the teacher's work load. In order to compensate this collateral effect, this study introduces another methodological contribution which adds on pedagogical advantages. The first correction will be conducted by peers from the same class who review their peers' work and conduct a pre-evaluation suggesting weak and strong points as well as possible improvements. A participative classroom where 
students have shared responsibilities and proactive attitudes on their own work will increase their autonomy, learning capacity and self-control. Boud (1986) estimates that selfassessment and peer's evaluation can reduce teacher's work up to 30\%. Moreover, student's self-assessment methods are as good as those involving the teacher -as long as some conditions are fulfilled- and also have positive effects on learning (Bretones, 2008).

Literature suggest that self-assessment works better using rubrics. Andrade (2000) define rubrics as a way to communicate expectations for an assignment, providing focused feedback on works in progress, and grading final products. Reddy and Andrade (2010) state that rubrics articulate the expectations for an assignment by listing the assessment criteria and by describing levels of quality in relation to each of these criteria. Rubrics tend to be quite informative for students, thereby helping them think, learn, and produce high quality work.

In contrast to other studies, our work aims to investigate the effects of this learning experience, i.e., dual-evaluation with peer's assessments (DEPA method), on the achievement and development of generic skills and abilities, that is, generic competencies achieved by students. For example, Topping (1998), Falchikov and Goldfinch (2000), Dochy et al. (1999) have focused on the reliability and effectiveness of peer-assessment, however, they do not study competencies achievement.

The analysis presented in this paper is the outcome of an innovative education project (IEP) developed in the Facultad de Ciencias Económicas y Empresariales (Universidad Complutense de Madrid). A total of 186 students receive the double-correction assessment using rubrics. The learning experience is conducted in 4 different subjects from three different Bachelor's degrees related to Economics and Business.

The article is structured as follows: Section 2 describes the learning experience and the DEPA method in practice; Section 3 shows the results, and Section 4 presents the main conclusions.

\section{DEPA method in practice}

The participants in the learning experience are 187 students enrolled in four different subjects corresponding to three different Bachelor's degrees (Bd): Microeconomics, 1-year $\mathrm{Bd}$ in Economics; Macroeconomics, 2-year Bd in Business Administration; Empirical Finance, 3th year Bd in Baking, Finance and Insurance; and Applied Econometrics, 4-year $\mathrm{Bd}$ in Economics (see Table 1). This variety of subjects, years and Bds enriches the analysis as there are huge differences between them subjects. This also permits us to design two different kind of homework assignment for student: practical exercises and empirical analyses. 
In particular, for Macroeconomic I (MA) and Microeconomic I (MI), the assignment is a practical exercise in which students must answer with detail some questions using theoretical knowledge on the subject. For Applied Econometric (AE) and Empirical Finance (EF), the assignment is an empirical analysis in which students must analyze a set of real data to test several (economic or financial) hypothesis with econometric and statistical tools and make a formal report summarizing the most relevant results.

We are attentive to the importance of involving rubrics in formative feedback. The rubric is a useful assessment tool for peer-assessment by students that give graduations of quality and criteria that are easy to follow (Andrade, 2000, Reddy and Andrade, 2010). By scaffolding the criteria, rubrics not only allow students to grade easily peer assignments, they also permit them to better understand the requirements to accomplish their own assignment. For this learning experience, the lecturers design a bespoke rubric for each subject that has two essential features: evaluation criteria (i.e., the criteria that describe the the different dimensions that determine the quality of the assignment) and the rating scale to assess the performance for each criterion (i.e., the detailed explanation of students' skill, proficiency and standard in order to attain a particular level of achievement). For the rating scale we use a simple Liker-scale that appears in the columns of the rubric matrix.

We implement the learning action through the workshop activity of Moodle 2.6. that allow the collection, review, and peer assessment of students' assignments. Both the allocation of submissions and the rubric matrix are configured by the lecturer in the workshop settings. Reviewers were anonymous.

To launch this learning experience, the lecturers distribute a document with a detailed assignment description, with detailed information about deadlines to make and deliver the task, and the rubric to the student audience. They read and discuss this document in the class room, explaining each phase of the activity and the rubric to the students. They also explain how the final grade will not only depend on how students meet the assignment objectives, but also depend on the quality of the assessment that they make of their peers. In the final phase, the lecturer evaluate both the assignment quality and the performance of students in the peer-assessment activity and give a final grade.

\section{Students' assessment of the learning experience}

We gather the student reflection on the innovative learning experience through an anonymous, non-compulsory completion of a bespoke module survey in which students must assess to what extent the experience has contributed to improving their skills. According to the Tuning Project (González and Wagenaar, 2003), competency is defined as the set of knowledge and skills that the student is expected to master and understand after completing the learning process. The survey focuses on generic competencies (independent 
of the subject and transferable between areas of knowledge). We follow the classification of the Tuning Project, which distinguishes three types of generic competencies: Instrumental competencies: cognitive, methodological, technological and linguistic abilities; Interpersonal competencies: individual capacities such as social skills (social interaction and cooperation); and Systemic competencies: skills and abilities related to global systems (combination of understanding, sensitivity and knowledge, for this it is necessary to previously acquire instrumental and interpersonal skills). The survey consisted of two parts: Firstly, it collects personal details that allow analyze if the student characteristics could influence their evaluation. Secondly, it collects the students' valuation on the degree of success of the learning experience in terms of achievement of generic competencies. We select 17 competencies from the Tuning Project and described by González and Wagenaar (2003): 6 instrumental; 7 systemic and 4 interpersonal competencies. The survey requires that students value the contribution of the experience to achieve these generic competencies by using Likert scale from 1 to 5 , where 1 indicates minimum contribution and 5 maximum contribution.

The population consisted of 187 students (65 students in Microeconomics, 63 in Macroeconomics, 16 in Empirical Finance and 43 students in Applied Econometrics). The final sample consisted of 107 respondents (67 \% of the population): $88 \%$ in Microeconomics, 32\% in Macroeconomics, 69\% in Empirical Finance and 86\% Applied Econometrics. The percentages are a good representation of the population.

Table 1. Distribution of students in the sample

\begin{tabular}{lccccc}
\hline & EF & AE & MA & MI & Total \\
\hline Male & 8 & 27 & 10 & 22 & $67(63 \%)$ \\
Female & 2 & 10 & 10 & 18 & $40(37 \%)$ \\
\hline Repeater & - & 1 & 5 & 9 & $15(14 \%)$ \\
Not repeater & 10 & 36 & 15 & 31 & $92(86 \%)$ \\
\hline Practical exercise & - & - & 20 & 40 & $60(56 \%)$ \\
Report & 10 & 37 & - & - & $47(44 \%)$ \\
\hline Business Degree & 10 & - & - & 40 & $50(47 \%)$ \\
Economics Degree & - & 37 & 20 & - & $57(53 \%)$ \\
\hline Total & 10 & 37 & 20 & 40 & 107 \\
& $(9 \%)$ & $(35 \%)$ & $(19 \%)$ & $(37 \%)$ & $(100 \%)$
\end{tabular}

The sample consists of 107 students. The percentages are out of the full sample size. Business include students from Business Administration and Banking, Finance and Insurance. 
Table 1 shows the percentages according to gender, subject, grade repetition (i.e. whether the students is a repeater in the subject), procedures designed, and degree. $63 \%$ of students were men and $37 \%$ women. $47 \%$ study Business Administration and Management or Banking, Finance and Insurance, and 53\% Economic. The distribution of the subjects was: 9\% Empirical Finance, 35\% Applied Econometrics, 19\% Macroeconomics and 37\% Microeconomics. The procedure implied reports (44\%) or practical exercises $(56 \%)$. The students which repeat the grade were $14 \%$.

A summary of the survey's results is shown in Table 2. Figures show the position that each competency has in the students' assessment about the utility of the learning experience to obtain and develop the competency. For each competency we show an order number from 1 to 17 , based on the average rating assigned by the students.

Table 2. Ranking of the students' valuation on the success of the DEPA method to achieve generic competencies

\begin{tabular}{|c|c|c|c|c|c|c|c|c|c|c|c|}
\hline & EF & $\mathbf{A E}$ & MA & MI & EAss & PAss & Fem & Male & Rep & NRep & Total \\
\hline \multicolumn{12}{|l|}{ I. Instrumental Competencies } \\
\hline $\begin{array}{l}\text { Ability for abstract thinking, } \\
\text { analysis and synthesis }\end{array}$ & 5 & 12 & 9 & 10 & 11 & 12 & 14 & 9 & 4 & 12 & 11 \\
\hline Ability to plan and manage time & 5 & 14 & 7 & 14 & 12 & 13 & 17 & 10 & 7 & 13 & 14 \\
\hline General basic knowledge & 6 & 7 & 4 & 7 & 6 & 6 & 11 & 7 & 3 & 8 & 8 \\
\hline $\begin{array}{l}\text { Knowledge and understanding of } \\
\text { the subject area and understanding } \\
\text { of the profession }\end{array}$ & 6 & 9 & 11 & 12 & 8 & 14 & 13 & 11 & 9 & 11 & 13 \\
\hline $\begin{array}{l}\text { Ability to communicate both } \\
\text { orally and through the written } \\
\text { word in first language }\end{array}$ & 7 & 17 & 8 & 8 & 15 & 9 & 12 & 13 & 8 & 10 & 12 \\
\hline $\begin{array}{l}\text { Ability to identify, pose and } \\
\text { resolve problems }\end{array}$ & 8 & 10 & 3 & 1 & 10 & 1 & 4 & 5 & 3 & 7 & 5 \\
\hline \multicolumn{12}{|l|}{ II. Interpersonal Competencies } \\
\hline $\begin{array}{l}\text { Ability to be critical and self- } \\
\text { critical }\end{array}$ & 1 & 5 & 5 & 11 & 3 & 10 & 9 & 4 & 7 & 6 & 7 \\
\hline Ability to work in a team & 4 & 6 & 8 & 4 & 5 & 4 & 3 & 8 & 7 & 5 & 6 \\
\hline Interpersonal and interaction skills & 10 & 11 & 10 & 15 & 13 & 15 & 10 & 15 & 10 & 15 & 15 \\
\hline $\begin{array}{l}\text { Ability to act on the basis of } \\
\text { ethical reasoning }\end{array}$ & 12 & 15 & 1 & 9 & 16 & 8 & 8 & 14 & 1 & 14 & 10 \\
\hline \multicolumn{12}{|l|}{ III. Systemic Competencies } \\
\hline $\begin{array}{l}\text { Ability to apply knowledge in } \\
\text { practical situations }\end{array}$ & 2 & 3 & 12 & 3 & 2 & 7 & 5 & 3 & 5 & 4 & 4 \\
\hline $\begin{array}{l}\text { Ability to undertake research at an } \\
\text { appropriate level }\end{array}$ & 3 & 13 & 13 & 16 & 9 & 17 & 15 & 16 & 12 & 17 & 16 \\
\hline $\begin{array}{l}\text { Capacity to learn and stay up-to- } \\
\text { date with learning }\end{array}$ & 2 & 4 & 6 & 6 & 3 & 5 & 7 & 1 & 6 & 3 & 3 \\
\hline $\begin{array}{l}\text { Ability to adapt to and act in new } \\
\text { situations }\end{array}$ & 5 & 8 & 9 & 9 & 7 & 11 & 6 & 12 & 11 & 9 & 9 \\
\hline $\begin{array}{l}\text { Capacity to generate new ideas } \\
\text { (creativity) }\end{array}$ & 9 & 16 & 13 & 13 & 14 & 16 & 16 & 17 & 13 & 16 & 17 \\
\hline $\begin{array}{l}\text { Ability to evaluate and maintain } \\
\text { the quality of work produced }\end{array}$ & 3 & 2 & 2 & 5 & 1 & 2 & 2 & 2 & 2 & 1 & 1 \\
\hline $\begin{array}{l}\text { Determination and perseverance in } \\
\text { the tasks given and responsibilities } \\
\text { taken }\end{array}$ & 11 & 1 & 11 & 2 & 4 & 3 & 1 & 6 & 7 & 2 & 2 \\
\hline
\end{tabular}

Note: Figures show the position that each competency has in the students' assessment about the utility of the learning experience to obtain and develop the competency. For each competency we show an order number from 1 to 17 , based on the average rating assigned by the students The competencies has been selected from the Tuning Project. 
The figures in Table 2 are computed is as follows: First we average the ratings given by the students surveyed for each competency. This give us a classification of competencies from more to less punctuated. Thus, we assign the order number to each competency, where 1 corresponds to the one that has obtained a higher score, i.e., that one that has been more favored by the experience according to the average opinion of the students. In some cases there are ties in the valuation, which is why sometimes there are two or more competencies with the same order number.

The columns of Table 2 depict the results for the full sample of students and grouping them according to: (1) the subject; (2) the type of assignment carried out by the students (empirical work and report vs. practical exercises); (3) gender; and (4) if the student is repeating the grade or not. Results in columns 1 to 4 point to the systemic competencies as the most rated by the students. For EF students the most developed competence is the critical and self-critical ability, for EA, they value more the perseverance for achievement, for MA students is the ethical commitment and for MI, is the most successful competition is problem solving. According to the kind of assignment (columns 5 and 6) the critical and self-critical ability is very relevant in empirical work while solving problems is in practices, in line with the peculiarities of each type of exercise. We found some interesting differences between male and female students (columns 7 and 8). For females, the most successful competency is perseverance for achievement, while for males it is the capacity to learn and stay up-to-date with learning. Regarding repeating character of the student (columns 9 and 10), repeaters put in the first place the ethical commitment, whereas for non-repeaters is the ability to evaluate and maintain the quality of work produced. This competency is also the most developed with the learning experience when we analyze the full sample of students (column 11).

\section{Conclusion}

This paper shows the implementation of a learning experience consisting on a doublecorrection with peer's assessments. The aims are to increase the students' motivation, and to prepare them with a range of transferable skills, increasing the active and reactive participation in their learning process. We implement a DEPA method in a variety of subjects corresponding to studies on Business and Economics and gather the students' reflections about how this learning experience has influenced the acquisition and development of a set of generic competencies. Overall, students have valued the process of active and creative reflection that the DEPA method implies. It also has helped to improve communication between lecturers and students as it forces the lecturer to clarify the evaluation criteria, as it must clearly specify what students expect, what the learning objectives are exactly, and what is the level of requirement to facilitate mutual correction among students. 
The results of the survey point to the suitability of the learning experience and the peerassessment to improve the development of capabilities related to the concern for the quality of work produced and the determination and perseverance in the tasks given and responsibilities taken. This result is pervasive regardless the characteristics of the students and the subject in which the DEPA has been applied. Interestingly, the kind of task is important to explain the students' opinion, being the ability to identify, pose and resolve problems the competency most developed for the students that solve a practical exercises, and the ability to evaluate and maintain the quality of work produced for the students that perform an empirical analysis.

\section{References}

Andrade, H. G. (2000). Using rubrics to promote thinking and learning. Educational Leadership 57 (5), 13-18.

Ashford-Rowe, K.; Herrington, J. \& Brown, C. (2014) Establishing the critical elements that determine authentic assessment. Assessment \& Evaluation in Higher Education, 39 (2), 205-222.

Bloom, B. S., Hastings, J. T. \& Madaus, G.F. (1971). Handbook of Formative and Summative Evaluation of Student Learning. New York: McGraw-Hill

Boud, D. (1986). Implementing Student Self-assessment. Green Guide No. 5, Higher Education Research and Development Society of Australasia. Sydney (Australia).

Bretones, A. (2008). Participación del alumnado de Educación Superior en su evaluación. Revista de Educación, 347, 181-202.

Carless, D. (2006). Differing perceptions in the feedback process. Studies in Higher Education, 31 (2), 219-233.

Covic, T. \& Jones, M.K. (2008). Is the essay resubmission option a formative or a summative assessment and does it matter as long as grades improve?. Assessment \& Evaluation in Higher Education, 33(1), 75-85.

De Miguel, M. (2009). Métodos y modalidades de enseñanza en la Educación Superior. Metodologías de enseñanza y aprendizaje para el desarrollo de competencias. Alianza Editorial. Madrid

Dochy, F., Segers, M. \& Sluijsmans, D. (1999). The use of self, peer and co-assessment in Higher Education: a review. Studies in Higher Education, 24(3), 331-350.

Ellery, K. (2008) Assessment for learning: a case study using feedback effectively in an essay-style test . Assessment \& Evaluation in Higher Education, 33(4), 421-429.

Falchikov, N. \& Goldfinch, J. (2000). Student peer assessment in Higher Education: A meta-analysis comparing peer and teacher marks. Review of Educational Research, 70(3), 287-322.

Gibbs, G. \& Simpson, C. (2004). Conditions Under Which Assessment Supports Students' Learning. Learning and Teaching in Higher Education, 1, 3-31. 
González, J. \& Wagenaar, R. (2003). Tuning Educational Structures in Europe: Informe Final. Fase Uno. Universidad de Deusto, Bilbao

Martínez, P. \& Echeverría, B. (2009). Formación basada en competencias. Revista de Investigación Educativa, 27(1), 125-147.

Reddy, Y.M. \& Andrade, H. (2010). A review of rubric use in higher education. Assessment \& Evaluation in Higher Education, 35 (4), 435-448.

Stiggins, R. J. (2002). Assessment crisis: The absence of assessment for learning. Phi Delta Kappan, 83(10), 758-765..

Topping, K. (1998). Peer assessment between students in colleges and universities, Review of Educational Research, 68(3), 249-276. 